\title{
Struktur komunitas laba-laba (Arachnida: Araneae) di Taman Nasional Bogani Nani Wartabone, Sulawesi Utara
}

\author{
Community structure of spiders (Arachnida: Araneae) in \\ Bogani Nani Wartabone National Park North Sulawesi
}

\author{
Roni Koneri*, Saroyo \\ Jurusan Biologi, Fakultas Matematika dan Ilmu Pengetahuan Alam Universitas Sam Ratulangi \\ Jalan Kampus Sam Ratulangi Bahu, Manado 95115
}

(diterima Januari 2015, disetujui Agustus 2015)

\begin{abstract}
ABSTRAK
Taman Nasional Bogani Nani Wartabone merupakan salah satu kawasan hutan tropis dataran rendah. Kawasan ini memiliki keanekaragaman artropoda yang tinggi dan salah satunya adalah labalaba. Penelitian ini bertujuan untuk mengkaji struktur dan komunitas laba-laba pada berbagai tipe habitat di Kawasan Taman Nasional Bogani Nani Wartabone, Sulawesi Utara. Pengambilan sampel dilakukan pada tiga tipe habitat, yaitu hutan primer, hutan sekunder, dan perkebunan. Penelitian dilaksanakan dari bulan Maret hingga Mei 2014 dengan menggunakan perangkap sumuran (pitfall trap) untuk laba-laba yang bergerak di permukaan tanah dan jaring ayun (sweep net) untuk laba-laba di atas kanopi vegetasi. Jumlah laba-laba yang diperoleh selama penelitian sebanyak 15 famili yang terdiri atas 71 genus, 129 morfospesies dan 1267 individu. Famili yang banyak ditemukan jumlah individunya adalah Tetragnathidae, sedangkan yang paling sedikit, yaitu Ctenizidae. Salticidae merupakan famili yang paling banyak ditemukan spesiesnya (30 spesies), sedangkan yang paling sedikit Agelenidae, Ctenidae, dan Ctenizidae dengan masing-masing satu spesies. Kelimpahan, kekayaan, keanekaragaman, dan kemerataan spesies tertinggi terdapat di kebun, sedangkan yang terendah di hutan sekunder. Indeks kesamaan komunitas laba-laba terbesar terdapat antara hutan primer dan hutan sekunder. Hasil penelitian ini diharapkan dapat dijadikan sebagai data dasar dan bahan informasi dalam menyusun strategi konservasi laba-laba di Sulawesi Utara.
\end{abstract}

Kata kunci: keanekaragaman, kekayaan, kelimpahan, laba-laba

\begin{abstract}
Bogani Nani Wartabone National Park is a tropical low land rain forest. This region has high diversity of arthropods, i.e. spider. The aims of this study was to analyze the Community structure of spiders of spiders (Arachnida: Araneae) in various types of habitat at Bogani Nani Wartabone National Park North Sulawesi. Sampling was carried out at three habitat types, namely primary, secondary, and farm. The research was conducted from March to May 2014 by using pitfall trap (to collect spiders that move on the ground) and sweep net (to collect the spideron vegetation canopy). The number of spiders obtained during the study of was 1267 speciments. The specimens collected are consists 15 families, 71 genera, and 129 morphospecies. The Family which most individual abundance is family Tetragnathidae and the least was Ctenizidae. Salticidae were the most common family of species (30 species), while the least were Agelenidae, Ctenidae and Ctenizidae where each family has one species. Abundance, richness, diversity and evenness of species was higher in the farm, while the lowest in the secondary forest. The highest similarity index of spider communities was between primary forests and secondary forests. The results of this research can be used as a diversity database of spiders for conservation strategies in North Sulawesi.
\end{abstract}

Key words: abudance, diversity, richness, spiders

\footnotetext{
*Penulis korespondensi: Roni Koneri. Jurusan Biologi Fakultas Matematika dan Ilmu Pengetahuan Alam, Universitas Sam Ratulangi Jalan Kampus Unsrat Bahu Manado, Sulawesi Utara 95115

Tel: +62-0431- 827932, Faks: +62-0431- 822568, Email: ronicaniago@yahoo.com
} 


\section{PENDAHULUAN}

Laba-laba tergolong dalam Filum Artropoda dan kelas Arachnida serta Ordo Araneae (Miller \& Sac 2011). Hewan ini merupakan kelompok terbesar dan memiliki keanekaragaman yang sangat tinggi dalam filum artropoda. Jumlah spesies laba-laba yang telah dideskripsikan pada saat ini sekitar 43.678 spesies, digolongkan dalam 111 famili dan 3600 genus (Anjali \& Prakash 2012). Sedangkan American Museum of Natural History (2016) melaporkan terdapat sebanyak 114 famili, 3977 genus dan 45.829 spesies labalaba. Diperkirakan jumlah jenis laba-laba di dunia seluruhnya dapat mencapai 170.000 (Lalisan et al. 2015).

Pada suatu ekosistem laba-laba memiliki peranan penting sebagai pemangsa terutama memangsa serangga sehingga berperan dalam mengendalikan populasi serangga hama. Laba-laba dapat dijadikan sebagai agens pengendali hayati yang potensial untuk berbagai spesies serangga hama karena laba-laba bersifat polifag (Chen \& Tso 2004; Miller \& Sac 2011; Samu et al. 2014; Deshmukh \& Raut 2014). Berdasarkan peranan ini laba-laba mempunyai arti penting dalam rantai makanan. Laba-laba juga memiliki peran dalam pertanian, perkebunan, dan perumahan, yaitu untuk melindungi dari serangga-serangga perusak (Mahalakshmi \& Jeyaparvathi 2014; Memah et al. 2014).

Kerusakan hutan akan berdampak terhadap keanekaragaman laba-laba dan mempengaruhi siklus nutrisi dan materi pada ekosistem tersebut. Beberapa penelitian tentang keanekaragaman labalaba telah dilakukan, diantaranya keanekaragaman laba-laba pada berbagai habitat di Taiwan (Chen \& Tso 2004), keanekaragaman laba-laba dan hubungannya dengan heterogenitas habitat (Abdelmoniem et al. 2003; Cabili \& Nuneza 2014; Vedel et al. 2103), keanekaragaman laba-laba pada hutan primer dan hutan terganggu di daerah tropis (Floren \& Reinhold 2005). Komposisi dan keanekaragaman laba-laba pada lima tipe vegetasi (Uniyal \& Hore 2008), komposisi dan keanekaragaman laba-laba pada kanopi pohon (Sorensen 2004).

Penelitian laba-laba yang telah dilakukan di Indonesia diantaranya kelimpahan dan keanekaragaman laba-laba pada kanopi di hutan hujan tropis Sulawesi (Smith \& Stork 1994). Komposisi dan komunitas laba-laba pada hutan hujan tropis Borneo (Smith \& Stork 1995). Komunitas laba-laba pada perkebunan kakao di Sulawesi Tengah (Stenchly 2010) dan bioekologi laba-laba pada bentang alam persawahan di Cianjur, Jawa Barat (Suana 2005).

Penelitian laba-laba di Sulawesi Utara masih sangat kurang dibandingkan dengan kepulauan lainnya. Beberapa penelitian masih terbatas pada lahan pertanian, seperti keanekaragaman labalaba pada berbagai lahan pertanian di Sulawesi Utara (Memah et al. 2014). Data tentang struktur komunitas laba-laba pada habitat hutan di Sulawesi Utara belum tersedia. Padahal Sulawesi merupakan lokasi dengan kecepatan kerusakan hutan cukup tinggi, yaitu $67 \%$ lebih habitat hutan basah produktif selama dua dasawarsa untuk keperluan kayu dan pertanian (Lee et al. 2001).

Kerusakan hutan juga terjadi Taman Nasional Bogani Nani Wartabone (TNBNW) luas hutan dari 300.000 ha pada tahun 1982 menjadi 287.115 ha pada tahun 2010 (Kawuwung 2010). Penurunan luas ini disebabkan oleh fragmentasi hutan menjadi area pertanian, permukiman, perladangan berpindah, penebangan kayu secara berlebihan, pencurian spesies flora. dan pertambangan di kawasan hutan. Struktur komunitas laba-laba pada kawasan TNBNW pada saat ini belum pernah diteliti dan dipublikasikan. Padahal data ini sangat penting sebagai database keanekaragaman dan dasar dalam memformulasikan strategi konservasi laba-laba di Sulawesi Utara. Berdasarkan hal tersebut maka perlu dilakukan penelitian tentang struktur komunitas laba-laba di Kawasan Taman Nasional Bogani Nani Wartabone, Sulawesi Utara. Penelitian ini bertujuan untuk mengkaji struktur komunitas laba-laba pada berbagai tipe habitat di Kawasan Taman Nasional Bogani Nani Wartabone, Sulawesi Utara.

\section{BAHAN DAN METODE}

\section{Lokasi penelitian}

Penelitian ini dilaksanakan di Taman Nasional Bogani Nani Wartabone (TNBNW), Sulawesi Utara. Secara geografis, kawasan ini terletak pada 
garis lintang antara $0^{\circ} .20^{\prime}-0^{\circ} .52^{\prime} \mathrm{LU}$ dan $123^{\circ} .06^{\prime}-$ $124^{\circ} .18^{\prime}$ BT (Gambar 1). Penelitian dilaksanakan pada tiga habitat, yaitu hutan primer, hutan sekunder, dan lahan perkebunan.

\section{Pengambilan sampel dan identifikasi}

Pengambilan sampel dilakukan mulai bulan Maret-Mei 2014 dengan cara membuat tiga plot pada masing-masing habitat dengan luas $50 \mathrm{~m} \mathrm{x}$ $50 \mathrm{~m}$ dan jarak antar plot $500 \mathrm{~m}$. Pada setiap plot dibuat empat transek dengan panjang $50 \mathrm{~m}$ dan jarak antar transek $15 \mathrm{~m}$. Pengambilan sampel menggunakan perangkap sumuran (pitfall trap) dan jaring ayun (sweep net). Perangkap sumuran untuk mengkoleksi laba-laba yang bergerak di permukaan tanah, sedangkan jaring ayun untuk laba-laba yang mendiami tajuk vegetasi (Vincent \& Hadrien 2013).

Perangkap sumuran yang digunakan dalam penelitian ini terbuat dari gelas plastik (volume $220 \mathrm{ml}$, diameter $=5,3 \mathrm{~cm}$ dan tinggi $=9,8 \mathrm{~cm}$ ) yang ditanam di tanah (Uniyal \& Hore 2008). Gelas plastik diisi dengan campuran cairan dengan komposisi air 1 liter : detergen 3 sendok makan : garam dapur 3 sendok makan, yang dituangkan sampai setengah dari tinggi wadah, permukaan wadah dibuat rata dengan tanah. Sebanyak 4 perangkap sumuran dipasang pada satu transek dengan jarak antar perangkap sejauh $10 \mathrm{~m}$. Perangkap dipertahankan tetap terpasang selama 3 x 24 jam. Sampel laba-laba yang terjebak disimpan dalam tabung pelastik yang telah diisi alkohol 95\%.

Pengambilan sampel dengan menggunakan jaring ayun dilakukan dengan mengayunkan jaring sebanyak 100 kali ayunan pada setiap transek. Koleksi laba-laba dengan teknik jaring ayun dilakukan antara pukul 09:00-12:00. Jaring berbentuk kerucut dengan kedalaman $60 \mathrm{~cm}$, diameter 300-380 cm, dan panjang tongkat jaring disesuaikan dengan tinggi tanaman.

Pengambilan sampel laba-laba dengan perangkap sumuran dan jaring ayun dilakukan setiap bulan selama 3 bulan. Laba-laba yang dikoleksi di lapang disimpan dalam tabung plastik yang telah diisi alkohol 95\%. Sampel yang berasal dari perangkap sumuran dan jaring ayun kemudian diidentifikasi sampai level morfospesies dan dihitung jumlah individunya. Proses identifikasi dilakukan berdasarkan ciri morfologi eksternal

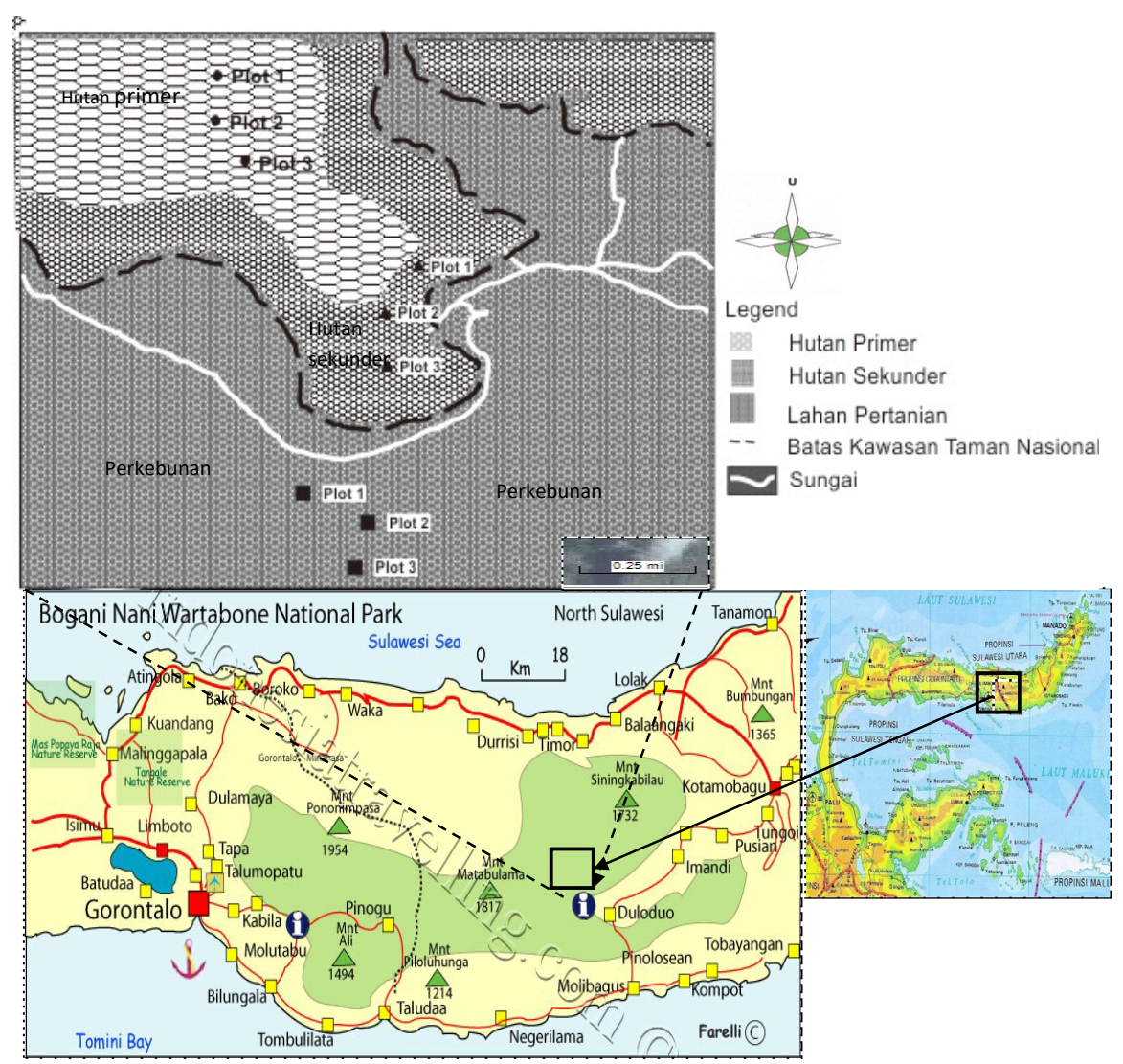

Gambar 1. Peta lokasi penelitian di Taman Nasional Bogani Nani Wartabone. 
(morfospesies) dengan menggunakan buku Borror et al. (1996), Levi \& Levi (1990), dan Barrion \& Litsinger (1995).

\section{Analisis data}

Keanekaragaman spesies laba-laba dianalisis dengan menggunakan indeks keanekaragaman menurut Shannon \& Weaner (H') (Hsieh et al. 2003).

$$
-\sum_{i=l}^{s}\left(\mathrm{P}_{\mathrm{i}}\right)\left(\ln \mathrm{P}_{\mathrm{i}}\right)
$$

Nilai H' berkisar antara 1,5-3,5 (Magurran 1988), dengan 1,5: keanekaragaman rendah; 1,53,5: keanekaragaman sedang; 3,5: keanekaragaman tinggi.

Kemerataan spesies dihitung menggunakan indeks kemerataan Shannon (Lone et al. 2015). Sedangkan analisis perbedaan kelimpahan, kekayaan, keanekaragaman, dan kemerataan spesies lala-laba antar habitat menggunakan perangkat lunak statistika versi 6, Anova satu arah (One-way Anova) dan uji Tukey's pada taraf kepercayaan 95\% (StatSoft 2001; Ohsawa 2005).

Kesamaan komunitas laba-laba antar tipe habitat dianalisis dengan menggunakan indeks kesamaan Sorensen dan data yang digunakan adalah kehadiran dan ketidakhadiran spesies labalaba (Magurran 1988). Nilai kesamaan (indeks Sorensen) digunakan untuk membuat analisis kelompok (cluster analysis) (Krebs 1999). Analisis kelompok setiap komunitas disusun secara hirarki dalam bentuk dendogram. Dendogram dibuat menggunakan perangkat lunak Minitab 16. Pengelompokkan menggunakan Average Linkage.

\section{HASIL}

\section{Keanekaragaman laba-laba}

Jumlah laba-laba yang didapatkan selama penelitian berdasarkan identifikasi morfospesies sebanyak 15 famili yang terdiri atas 71 genus, 129 morfospesies, dan 1267 individu. Famili yang paling banyak ditemukan adalah Tetragnathidae sebanyak 22,08\%, sedangkan kelimpahan terendah, yaitu Ctenizidae sebanyak 0,08\%, kemudian disusul oleh Agelenidae dan Ctenidae dengan kelimpahan masing-masing sebesar $0,16 \%$. Salticidae merupakan famili yang paling banyak ditemukan spesiesnya, kemudian disusul oleh Areneidae dan Theridiidae. Famili yang paling sedikit jumlah spesies yang ditemukan adalah Agelenidae, Ctenidae, dan Ctenizidae dengan masing-masing satu spesies (Tabel 1).

Distribusi laba-laba berdasarkan tipe habitat didapatkan bahwa dari 15 famili yang didapatkan, semua famili tersebut ditemukan pada hutan primer, 11 famili ditemukan pada semua tipe habitat, 3 famili (Agelnidae, Ctenidae dan Ctenizidae) hanya didapatkan pada hutan primer dan tidak ditemukan pada habitat lainnya. Famili Pholcidae ditemukan di hutan primer dan hutan sekunder, tapi tidak ditemukan pada lahan perkebunan (Tabel 1).

Struktur komunitas laba-laba menunjukkkan bahwa kelimpahan, kekayaan, keanekaragaman, dan kemerataan spesies tertinggi ditemukan pada lahan perkebunan, sedangkan yang terendah di hutan sekunder (Gambar 2). Nilai keanekaragaman dengan menggunakan Indeks Shannon pada hutan primer sebesar 2,81, hutan sekunder 2,62 dan indeks tertinggi terdapat pada lahan perkebunan $(3,17)$ (Gambar 2). Nilai Indeks Shannon pada ketiga tipe habitat ini masih berada dalam satu kategori, yaitu keanekaragaman sedang yang nilainya berkisar antara 1,5-3,5. Hasil uji statistik menunjukkan bahwa kekayaan, kelimpahan, dan keanekaragaman spesies berbeda nyata antar habitat, sedangkan kemerataan spesies tidak berbeda nyata. Kelimpahan spesies tertinggi pada lahan perkebunan dan berbeda nyata dengan hutan primer dan hutan sekunder, sedangkan hutan primer tidak menunjukkan perbedaan yang nyata dengan hutan sekunder $\left(\mathrm{F}_{2,9}=94,97 ; \mathrm{P}=0,000\right)$. Kekayaan spesies di lahan perkebunan berbeda nyata dengan hutan primer dan hutan sekunder, hal yang sama juga terjadi antara hutan primer dan hutan sekunder $\left(\mathrm{F}_{2,9}=61,89 ; \mathrm{P}=0,000\right)$. Indeks keanekaragaman tertinggi ditemukan pada lahan perkebunan dan berbeda nyata dengan hutan sekunder, tapi tidak berbeda nyata dengan hutan primer $\left(\mathrm{F}_{2,9}=4,62 ; \mathrm{P}\right.$ $=0,041)$. Kemerataan spesies tertinggi ditemukan pada lahan perkebunan dan indeks ini tidak menunjukkan perbedaan yang nyata antar habitat penelitian $\left(\mathrm{F}_{2,9}=0,053 ; \mathrm{P}=0,949\right)($ Gambar 2$)$.

\section{Kesamaan komunitas laba-laba}

Kesamaan komunitas laba-laba antar habitat menunjukkan indeks kesamaan terbesar antara hutan primer dan hutan sekunder dengan nilai indeks kesamaan sebesar 0,53 atau 53\%, kemudian antara hutan sekunder dan perkebunan 0,35 (35\%). 
Tabel 1. Jumlah famili, genera, spesies dan individual laba-laba yang ditemukan pada tiga tipe habitat di Taman Nasional Bogani Nani Wartabone Sulawesi Utara

\begin{tabular}{|c|c|c|c|c|c|c|c|c|c|c|}
\hline \multirow{3}{*}{ Famili } & \multirow{3}{*}{$\begin{array}{c}\text { Jumlah } \\
\text { genera }\end{array}$} & \multirow{3}{*}{$\begin{array}{c}\text { Jumlah } \\
\text { morfo } \\
\text { spesies }\end{array}$} & \multicolumn{6}{|c|}{ Habitat/ jumlah individu } & \multirow{2}{*}{\multicolumn{2}{|c|}{ Grand total }} \\
\hline & & & \multicolumn{2}{|c|}{ Hutan primer } & \multicolumn{2}{|c|}{ Hutan sekunder } & \multicolumn{2}{|c|}{ Perkebunan } & & \\
\hline & & & Jumlah & $\%$ & Jumlah & $\%$ & Jumlah & $\%$ & Jumlah & $\%$ \\
\hline Tetragnathidae & 4,00 & 11,00 & 52,00 & 4,07 & 72,00 & 5,64 & 158,00 & 12,37 & 282,00 & 22,08 \\
\hline Araneidae & 11,00 & 23,00 & 43,00 & 3,37 & 28,00 & 2,19 & 135,00 & 10,57 & 206,00 & 16,13 \\
\hline Oxyopidae & 1,00 & 7,00 & 6,00 & 0,47 & 4,00 & 0,31 & 179,00 & 14,02 & 189,00 & 14,80 \\
\hline Thomisidae & 9,00 & 18,00 & 15,00 & 1,17 & 10,00 & 0,78 & 163,00 & 12,76 & 188,00 & 14,72 \\
\hline Salticidae & 20,00 & 30,00 & 40,00 & 3,13 & 40,00 & 3,13 & 53,00 & 4,15 & 133,00 & 10,42 \\
\hline Theridiidae & 13,00 & 20,00 & 77,00 & 6,03 & 14,00 & 1,10 & 21,00 & 1,64 & 112,00 & 8,77 \\
\hline Lycosidae & 1,00 & 2,00 & 16,00 & 1,25 & 9,00 & 0,70 & 35,00 & 2,74 & 60,00 & 4,70 \\
\hline Sparassidae & 2,00 & 3,00 & 26,00 & 2,04 & 18,00 & 1,41 & 3,00 & 0,23 & 47,00 & 3,68 \\
\hline Clubionidae & 1,00 & 5,00 & 8,00 & 0,63 & 16,00 & 1,25 & 11,00 & 0,86 & 35,00 & 2,74 \\
\hline Zodariidae & 2,00 & 2,00 & 3,00 & 0,23 & 6,00 & 0,47 & 2,00 & 0,16 & 11,00 & 0,86 \\
\hline Pholcidae & 2,00 & 2,00 & 4,00 & 0,31 & 2,00 & 0,16 & 0,00 & 0,00 & 6,00 & 0,47 \\
\hline Uloboridae & 2,00 & 2,00 & 1,00 & 0,08 & 1,00 & 0,08 & 1,00 & 0,08 & 3,00 & 0,23 \\
\hline Agelenidae & 1,00 & 1,00 & 2,00 & 0,16 & 0,00 & 0,00 & 0,00 & 0,00 & 2,00 & 0,16 \\
\hline Ctenidae & 1,00 & 1,00 & 2,00 & 0,16 & 0,00 & 0,00 & 0,00 & 0,00 & 2,00 & 0,16 \\
\hline Ctenizidae & 1,00 & 1,00 & 1,00 & 0,08 & 0,00 & 0,00 & 0,00 & 0,00 & 1,00 & 0,08 \\
\hline Total & 71,00 & 128,00 & 296,00 & 23,18 & 220,00 & 17,23 & 761,00 & 59,59 & 1277,00 & 100,00 \\
\hline
\end{tabular}
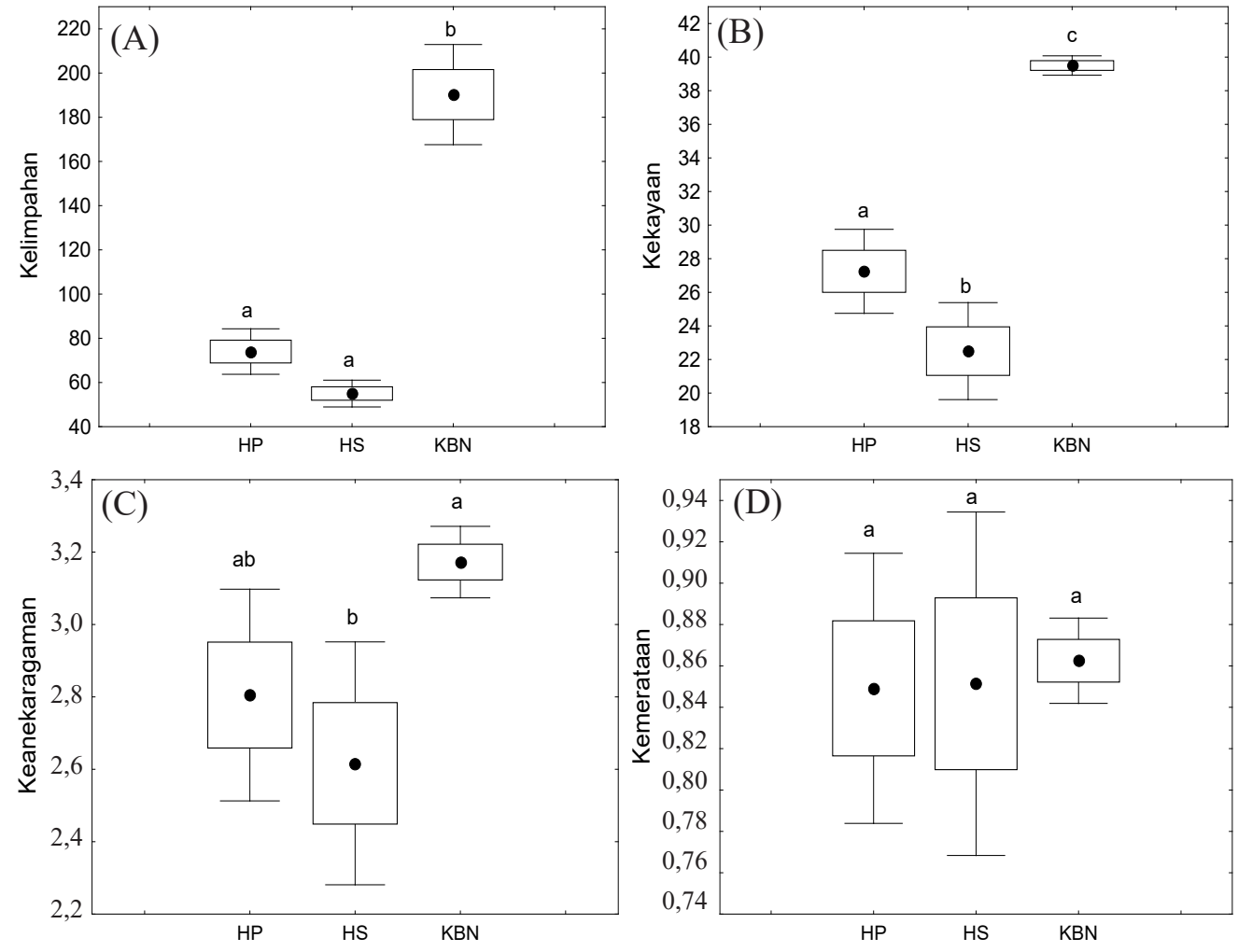

Gambar 2. A: Kelimpahan; B: kekayaan; C: keanekaragaman (H'); dan d: kemerataan (E) laba-laba pada tiga tipe habitat di TNBNW Sulawesi Utara. HP: hutan primer; HS: hutan sekunder; KBN: kebun; $\bullet$ : rata-rata; $\square: \pm$ galat baku $( \pm \mathrm{SE})$; 工: \pm simpangan baku $( \pm \mathrm{SD})$. Huruf yang sama pada gambar yang sama tidak berbeda nyata menurut uji Tukey pada taraf kepercayaan $95 \%$. 
Indeks kesamaan Sorensen komunitas laba-laba terkecil antara hutan primer dan perkebunan dengan nilai 0,26 (26\%). Hasil dendogram dengan menggunakan Cluster variable dan Average Lingkage terdapat dua pengelompokkan yang jelas, yaitu hutan primer satu kelompok dengan hutan sekunder (Gambar 3). Hal ini menunjukkan bahwa komunitas laba-laba di hutan primer banyak kesamaannya dengan hutan sekunder dibandingkan dengan habitat perkebunan.

\section{PEMBAHASAN}

Tetragnathidae merupakan famili yang memiliki kelimpahan tertinggi, dan dominan ditemukan pada lahan perkebunan. Famili ini umumnya melimpah pada rerumputan atau vegetasi rendah, dan sangat jarang ditemukan pada pohon yang tinggi. Tetragnathidae merupakan laba-laba pembuat jaring. Hasil penelitian (Herlinda et al 2014) melaporkan bahwa Tetragnathidae merupakan laba-laba pembuat jaring. Sebaliknya, Tetragnathidae, seperti Tetragnatha vermiformis Emerton ditemukan pada permukaan tanah. Hal ini dapat disebabkan oleh perilaku spesies tersebut walaupun pembuat jaring, tetapi mampu bergerak dan berjalan di permukaan tanah dan air. Beberapa peneliti melaporkan bahwa Tetragnathidae merupakan famili yang dominan ditemukan selama penelitian (Barrion et al. 2012; Hsieh \& Linsenmair 2012; Suana 2005).
Rendahnya kelimpahan Ctenizidae, Agelenidae, dan Ctenidae disebabkan famili tersebut tidak memiliki penyebaran yang luas di alam. Hal ini ditunjukkan dari beberapa hasil penelitian yang dilakukan baik di Indonesia maupun di Negara lain, seperti Suana (2005), Suana \& Haryanto (2013), Sudhikumar et al. (2005), dan Barrion et al. (2012) tidak menemukan famili laba-laba tersebut dalam penelitiannya. Penelitian Sorensen (2004) menemukan Agelenidae dan Ctenidae masingmasing sebanyak satu spesies dengan jumlah individu Agelenidae sebanyak 2, sedangkan Ctenidae hanya 1 individu.

Kelimpahan dan keanekaragaman labalaba tertinggi ditemukan di lahan perkebunan. Hasil ini sesuai dengan penelitian Shochat et al. (2004) yang melaporkan bahwa kelimpahan dan keanekaragaman laba-laba tertinggi ditemukan pada lahan perkebunan.

Kehadiran laba-laba pada suatu ekosistem sangat dipengaruhi oleh faktor lingkungan, seperti suhu, kelembaban, angin, dan intensitas cahaya. Faktor biologis, seperti tipe vegetasi, ketersediaan makanan, pesaing, dan musuh-musuhnya merupakan faktor-faktor yang membatasi kehadiran laba-laba pada suatu ekosistem. Tingginya kelimpahan laba-laba pada perkebunan disebabkan oleh melimpahnya serangga hama yang berada di daerah tersebut. Pada lahan perkebunan selain ditanam tanaman budi daya di sekitarnya juga terdapat tumbuhan lainnya dari famili Asteraceae dan Poaceae. Keberadaan vegetasi bukan-tanaman di sekitar tanaman budi daya juga turut menambah

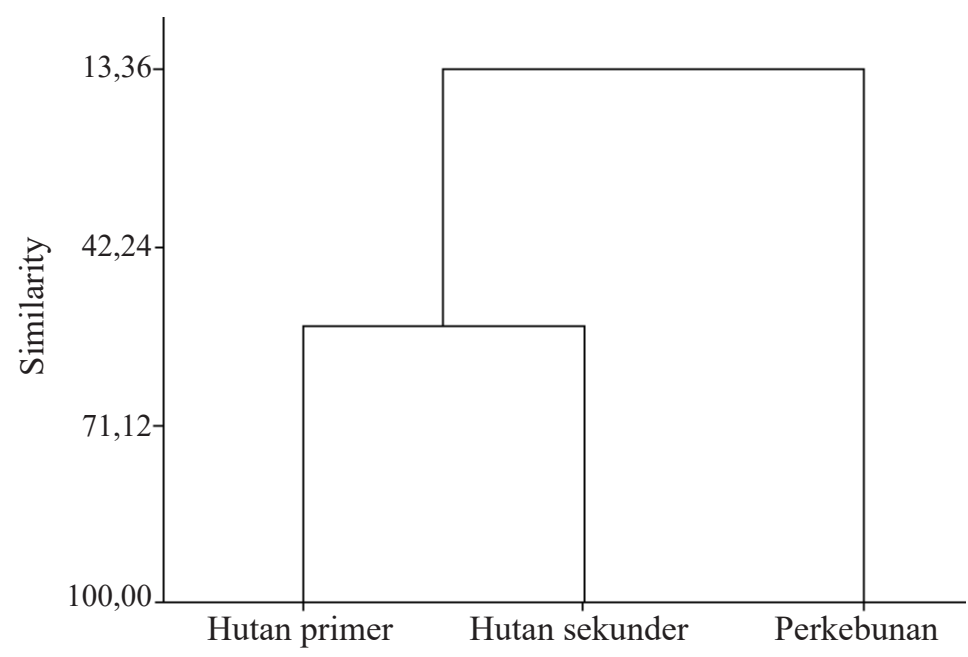

Gambar 3. Dendogram kesamaan komunitas laba-laba pada tiga tipe habitat di Taman Nasional Bogani Nani Wartabone, Sulawesi Utara. 
kompleksitas lanskap perkebunan. Kehadiran tanaman berbunga ini dapat menyebabkan banyak serangga yang merupakan mangsa dari laba-laba dapat hidup pada vegetasi tersebut (Suana \& Yaherwandi 2009). Struktur fisik habitat, seperti adanya daun, ranting, dan bagian tanaman lainnya merupakan tempat laba-laba untuk melekatkan benang-benang bingkainya. Pelekatan benangbenang bingkai ini merupakan tahap awal yang dijalani laba-laba dalam pemilihan tempat membuat jaring. Habitat dengan struktur yang kompleks akan memiliki kenaekaragaman labalaba yang tinggi (Uniyal \& Hore 2008).

Pohon dan tumbuhan herbaseus yang terdapat di lahan perkebunan akan menyebabkan struktur semakin kompleks, hal ini akan berdampak terhadap keanekaragaman laba-laba (Galle 2014). Struktur vegetasi yang heterogen dan habitat yang kompleks menyediakan relung-relung bagi fauna dan akan membentuk jaring makanan (Uniyal \& Hore 2008). Suana (2005) dan Kamal et al. (2011) menyatakan bahwa keanekaragaman spesies umumnya akan meningkat sejalan dengan meningkatnya keragaman struktur habitat. Foelix (1996) menyatakan bahwa habitat yang ditumbuhi vegetasi lebat merupakan habitat yang dominan dihuni oleh laba-laba. Suana \& Yaherwandi (2009) melaporkan bahwa lanskap yang kompleks memicu keanekaragaman sumberdaya yang menjadi mangsa tambahan bagi predator. Kehadiran mangsa tambahan menjadikan populasi predator generalis, seperti laba-laba, terpelihara dalam kelimpahan yang tinggi.

Analisis kesamaan komunitas laba-laba menunjukkan bahwa komposisi spesies labalaba antara hutan primer dan hutan sekunder lebih banyak kesamaannya dibandingkan dengan perkebunan. Indeks tersebut juga menunjukkan bahwa komposisi laba-laba yang ditemukan di hutan primer dan hutan sekunder kesamaanya sekitar 53\%. Indeks kesamaan komunitas pada dua habitat (hutan primer dan hutan sekunder) tersebut masih digolongkan kategori rendah karena tidak mendekati $100 \%$. Komunitas laba-laba di hutan primer berbeda dengan lahan perkebunan karena nilai indeks kesamannya di bawah $50 \%$. Menurut Krebs (1999), komunitas berbeda jika indeks kesamaan komunitas yang dibandingkan kecil dari $50 \%$.

\section{KESIMPULAN}

Jumlah laba-laba yang diperoleh selama penelitian sebanyak 15 famili yang terdiri atas 71 genus, 129 morfospesies dan 1267 individu. Famili yang banyak ditemukan jumlah individunya adalah Tetragnathidae, sedangkan yang paling sedikit, yaitu Ctenizidae. Kelimpahan, keakayaan, keanekaragaman, dan kemerataan spesies teringgi ditemukan pada lahan perkebunan, sedangkan yang terendah pada hutan sekunder. Indeks keanekaragaman Shanon \& Weaner (H' pada semua tipe habitat yang diamati termasuk dalam kategori sedang, dengan nilai berkisar antara 1,5-3,5. Indeks kesamaan komunitas laba-laba tertinggi terdapat antara hutan primer dan hutan sekunder.

\section{UCAPAN TERIMA KASIH}

Penulis mengucapkan terima kasih kepada Dit. Litabmas Direktorat Jenderal Pendidikan Tinggi yang telah mendanai penelitian ini melalui penelitian Hibah Kompetensi tahun anggaran 2014.

\section{DAFTAR PUSTAKA}

Abdelmoniem HE, Zalat S, El-Naggar M, Ghobashy A. 2003. Spider diversity in relation to habitat heterogeneity and an altitudinal gradient in South Sinai, Egypt. Egyptian Journal of Biology 5:129-137.

American Museum of Natural History. 2016. The World Spider Catalog Version 17.0. Currently valid spider genera and species. Available at: http://www.wsc.nmbe.ch/statistics/\# [accessed 2 Februari 2016].

Anjali, Prakash S. 2012. Diversity of spiders (Aranea) from semi-arid habitat of agra (India). Indian Journal of Arachnology 1:66-72.

Barrion AT, Litsinger JA. 1995. Riceland spider of South and Southeast Asia International Rice Research Institute. Manila: CAB International.

Barrion AT, Villareal SS, Catinding JLA, Cai D, Yuan QH, Heong KL. 2012. The spider fauna in tha rice agricultural landscape of Hainan Island, China: Composition, Abundance and Feeding 
Structure. The Asian International Journal of Life Sciences 21:625-651.

Borror BJ, Triplehorn CA, Johnson, NF. 1996. Pengenalan Pelajaran Serangga. Ed. ke-6. Yogyakarta: Gajah Mada University Press.

Cabili MHD, Nuneza OM. 2014. Species diversity of cave-dwelling spiders on Siargao Island, Philippines. International Journal of Plant, Animal and Environmental Sciences 4:392-399.

Chen KC, Tso IM. 2004. Spider diversity on Orchid Island, Taiwan: a comparison between habitats receiving different degrees of human disturbance Zoological Studies 43:598-611.

Deshmukh US, Raut NM. 2014. Seasonal diversity and status of spiders (Arachnida: Araneae) in Salbardi forest (Satpura Range), Maharashtra, India. Journal of Entomology and Zoology Studies 2:278-281. Available at: http://www. entomoljournal.com.

Foelix RF. 1996. Biology of Spider. $2^{\text {nd }}$ Ed. New York: Oxford University Press.

Floren A, Reinhold CD. 2005. Diversity of arboreal spiders in primary and disturbed tropical forests. Journal of Arachnology 33:323-333. doi: http:// dx.doi.org/10.1636/05-22.1.

Galle R, Schweger S. 2014. Habitat and landscape attributes influencing spider assemblages at lowland forest river valley (Hungary). Journal of Zoology 10:36-41.

Herlinda S, Manalu HCN, Aldina RF, Suwandi. 2014. Kelimpahan dan keanekaragaman spesies laba-laba predator hama padi ratun di sawah pasang surut. Jurnal HPT Tropika 14:1-7.

Hsieh YL, Lin YS, Tso IM. 2003.Ground spider diversity in the Kenting uplifted coral reef forest, Taiwan: a comparison between habitats receiving various disturbances. Biodiversity and Conservation 12:2173-2194. doi: http://dx.doi. org/10.1023/A:1024591311548.

Hsieh YL. Linsenmair KE. 2012. Seasonal dynamics of arboreal spider diversity in temperate forest. Ecology and Evolution 2:768-777. doi: http:// dx.doi.org/10.1002/ece3.221.

KamalM, Yustian I, Rahayu S. 2011. Keanekaragaman jenis arthropoda di Gua Putri dan Gua Selabe Kawasan Karts Padang Bindu, OKU Sumatera Selatan. Jurnal Penelitian Sains 14:34-35.

Kawuwung FR. 2010. Potensi Taman Nasional Bogani Nani Wartabone, permasalahan dan konservasi pada tingkat pengembangan dan pengawasan. El-Hayah 1:15-18.

Krebs CJ. 1999. Ecological Methodology. $2^{\text {nd }} e d$. Menlo Park: Addison-Wesley.
Lalisan JA, Dupo ALB, Nuneza OM. 2015. Diversity of spiders along an elevational gradient in Mt. Pinukis, Zamboanga del Sur, Philippines. Journal of Biodiversity and Environmental Sciences 7:190-201.

Lee RJ, Riley J, Merril R. 2001. Keanekaragaman Hayati dan Konservasi di Sulawesi Bagian Utara. Jakarta: WCS-IP dan NRM.

Levi HW, Levi LR. 1990. Spider and Their Kin. New York: Golden Press.

Lone MA, Dar IY, Bhat GA. 2015. A study on ecology distribution and community diversity of spiders in Gulmarg Wildlife Sanctuary of Kashmir Himalaya. Jurnal of Ecology and the Natural Environment 7:81-89. doi: http://dx.doi. org/10.5897/JENE2015.0500.

Magurran AE. 1988. Ecological Diversity And Its Measurements. London: Croom Helm Limited. London. doi: http://dx.doi.org/10.1007/978-94015-7358-0.

Mahalakshmi R, Jeyaparvathi S. 2014. Diversity of spider fauna in the cotton field of Thailakulam, Virudhunagar District, Tamil Nadu, India. The Journal of Zoology Studies 1:12-18.

Memah VV, Tulung M, Warouw J, Maramis RRTD. 2014. Diversity of spider species in some agricultural crops in North Sulawesi, Indonesia. International Journal of Scientific \& Engineering Research 5:70-75.

Miller JA, Sac PD. 2011. Landscape biodiversity of tropical forest Spider communities in Vietnam (Arachnida: Araneae). Treubia 38:53-70

Ohsawa M. 2005. Species richness and composition of curculionidae (Coleoptera) in a conifer plantation, secondary forest, and old-growth forest in the central mountainous region of Japan. Ecology Researc 20:632-645. doi: http://dx.doi. org/10.1007/s11284-005-0080-7.

Samu F, Lengyel G, Szita E, Bidlo A, Odor P. 2014. The effect of forest stand characteristics on spider diversity and species composition in deciduous-coniferous mixed forests. The Journal of Arachnology 42:135-141. doi: http://dx.doi. org/10.1636/CP13-75.1.

Shochat E, Stefanov E, Whitehouse MEA, Faeth SH. 2004. Urbanization and spider diversity: influences of human modification of habitat structure and productivity. Ecological Applications 14:268-280. doi: http://dx.doi. org/10.1890/02-5341.

Smith RA, Stork NE.1994. Abundance and diversity of spiders from the canopy of tropical rainforests with particular reference to Sulawesi, Indonesia. 
Journal of Tropical Ecology 10:545-558. doi: http://dx.doi.org/10.1017/S0266467400008221.

Smith RA, Stork NE. 1995. Composition of spider communities in the canopies of rainforest trees in Borneo. Journal of Tropical Ecology 11:223-235. doi: http://dx.doi.org/10.1017/ S0266467400008695.

Sorensen LL. 2004. Composition and diversity of the spider fauna in tree canopy of a montane forest in Tanzania. Biodiversity and Conservation 13:437-452. doi: http://dx.doi.org/10.1023/ B:BIOC.0000006510.49496.1e.

StatSoft. 2001. Stastistica for windows, 6.0 statsoft Inc. Tulsa: Oklohoma.

Stenchly K. 2010. Spider Communities in Indonesian Cacao Agroforestry: Diversity, Web Density and Spatio-temporal Turnover. Dissertation. Göttingen: University of Göttingen

Suana IW. 2005. Bioekology of Spiders in Ricefield Landscape at Cianjur. West Java. Disertasi. Bogor: Institut Pertanian Bogor.

Suana IW, Yaherwandi. 2009. Aplikasi sistem informasi geografi (SIG) untuk mempelajari keragaman struktur habitat laba-laba pada lansekap pertanian di daerah aliran sungai (DAS) Cianjur. Jurnal Ilmu Dasar 10:147-152.
Suana IW, Haryanto H. 2013. Keanekaragaman laba-laba dan potensinya sebagai musuh alami hama tanaman jambu mete. Jurnal Entomologi Indonesia 10:24-25. doi: http://dx.doi. org/10.5994/jei.10.1.24.

Sudhikumar AV, Mathew MJ, Sunish E, Murugesan S, Sebastian PA. 2005. Preliminary student on the spider fauna in Mannavan Shola Forest, Kerala, India (Araneae). In: Deltshev C, Stoev P (Eds.), European Arachnology, Acta zoologica bulgarica (Suppl. No. 1). pp: 319-327.

Uniyal VP, Hore U. 2008. Diversity and composition of spider assemblages in five vegetation types of the Terai Conservation Area, India. The Journal of Arachnology 36:251-258. doi: http://dx.doi. org/10.1636/CT07-53.1.

Vincent V, Hadrien L. 2013. Standardized sampling protocol for spider community assessment in the neotropical rainforest. Journal of Entomology and Zoology Studies 1:18-34.

Vedel V, Rheims C, Murienne J, Brescovit Ad. 2013. Biodiversity baseline of the French Guiana spider Fauna. SpringerPlus 2:361. doi: http:// dx.doi.org/10.1186/2193-1801-2-361 . 